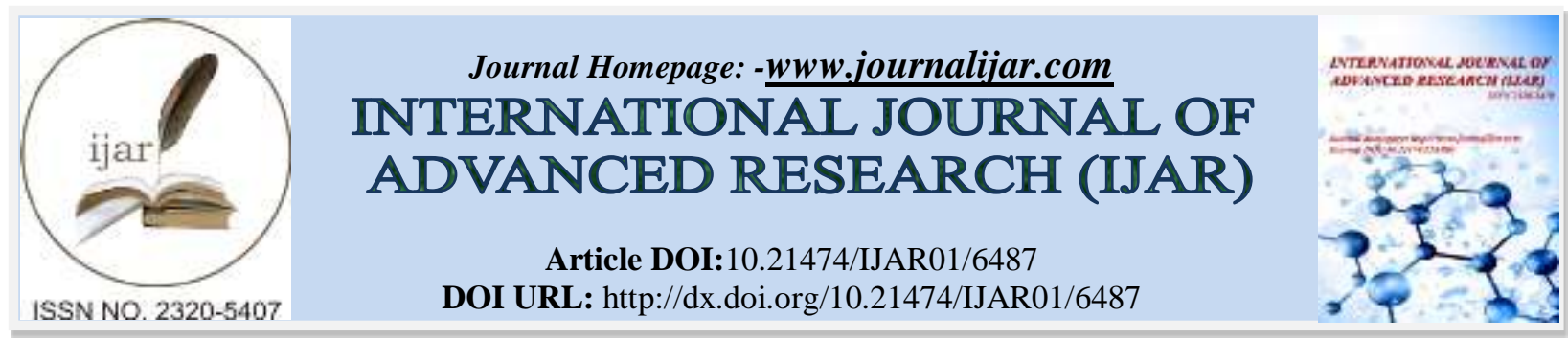

RESEARCH ARTICLE

\title{
LEADERSHIP BEHAVIOR AND EMOTIONAL INTELLIGENCE OF PUBLIC SECONDARY SCHOOL ADMINISTRATORS: BASIS FOR A PROPOSED LEADERSHIP PROGRAM.
}

Nicanor M. San Gabriel EdD.

Graduate School Professor, La Consolacion University Philippines Malolos City, Bulacan.

\section{Manuscript Info}

Manuscript History

Received: 09 December 2017

Final Accepted: 11 January 2018

Published: February 2018

Keywords:-

Leadership behavior, emotional intelligence, leadership capabilitybuilding program.

\section{Abstract}

The study was conducted to determine the leadership behavior and emotional intelligence of secondary mathematics head teachers in aid of developing a leadership capacity-building program. The study involved 19 head teachers in Mathematics and 221 Mathematics teachers in the public schools in the Division of Bulacan. The descriptive correlational method of research was used in the study, utilizing the Leader Behavior Description Questionnaire Form XII (LBDQ-Form XII) and the Emotional Intelligence Form (EI-Form) adapted from Stogdill, Silver, and Claret as primary data-gathering tools. The findings revealed that there were no significant differences as to leadership behaviors and as to emotional intelligence when grouped according to profile characteristics except for predictive accuracy when grouped according to the length of service. The findings also revealed that there was a negligible relationship between the leadership behaviors and the emotional intelligence behaviors of the head teachers. Based on the results of the assessments, a proposed leadership development program was conceptualized to further enhance the leadership and emotional intelligence capabilities of the head teachers.

Copy Right, IJAR, 2018,. All rights reserved.

\section{Introduction:-}

School leaders nowadays manifest different styles and behavior in managing and leading their subordinates. Some of them use modern style, but others still apply the traditional style of leadership. Some leaders are good and effective; some are efficient. Others need to improve their leadership skills.

According to Lenka (2012), the role of leadership in an organization is the behavior of an individual whereby he or she guides. The success and failure of a concern depend upon the quality of leadership. Hence, an inquiry into the leadership behavior in various educational organizations is of great significance to determine how a leader can become effective. In every social group, there are leaders, and there are followers. The former is active whereas the latter are passive. For survival, every society asks for more and better leaders. The insistence in the demand for leaders is evidently due to pressing needs of the environment. Anyone can lead, but not everyone can efficiently handle and organize human relationship. A leader is always an individual who has outstanding qualities of head and heart. The identification of an institution depends upon its head. Leadership is in demand in different fields and situations like social, political, cultural and educational. 
As mentioned by Kant (2012), modern educational organizations have grown more complex. There is a requirement for intelligent guidance and supervision in which only talented and creative people can give. The need of highly skilled leadership is, therefore, the psychology of the group. The leader has to provide good morale and sustain the influence which involves an attempt to affect the behavior through communication. Leadership is associated with certain goals and the means to achieve the group's. A good leader is not only able to command well but can extract from his followers the best of their abilities and aptitudes.

Research has confirmed the existence of strong ties between emotional intelligence and leadership. Peter Salovey and Jack Meyer defined emotional intelligence as a set of abilities to do with emotions and the processing of emotional information (Shapiro, 2007). In addition, Goleman (2001), considered as father of emotional intelligence, discussed that the role of leadership in relation to emotional intelligence and that the primary task of leaders is to keep his subordinates' morale high; and as they accomplish their tasks, the primal role of leader is emotional.

Emotional Intelligence shows the ability to understand one's feelings to detect the signs of emotional reactions and to influence others through emotional regulation and control. It is considered an essential tool for effective leadership. In his research, Goleman found out that emotional intelligence contributes to eighty percent of success in life and career while only twenty percent is for cognitive intelligent quotient (IQ). He concluded that emotional intelligence shapes the behavior of the leader and the best indicator of the leader and the best indicator of his or her leadership effectiveness (Goleman, 2002).

Moreover, many researchers have studied the behavior of the leader and how this would affect his followers. Recent researches in leadership tried to identify the characteristics of effective leaders. This resulted in two prominent theories: transactional and transformational leadership. Avolio and Bass (2002) stated that transactional theory, which is based on exchange, uses reward and punishment as an incentive to manipulate followers in performing tasks. Transformational leadership has been attributed with effecting change by influencing values, attitudes, and behaviors of others.

Head teachers in school organizations play a very significant role in the smooth running of educational institutions. The leadership behavior of the head teachers greatly affects the social climate of the various levels of education.

Based on the statements, it can be said that both leadership and emotional intelligence have something to do with the behavior of oneself and of the others including supervisors, subordinates, co-workers, and clients. While leadership is the ability of the leader to influence the values, attitudes and behaviors of the people; the emotional intelligence is the ability to read and understand one's feelings and those of others in a social context, to detect the signs of emotional reaction, and to utilize such knowledge to influence others through emotional regulation and control. As such, it represents a critically important competency for effective leadership.

Organizations like schools need good leaders in the form of head teachers. Head teachers are leaders next to the principal in each public school. They have teachers under their supervision. They are considered to be leaders and managers in the school. As head teachers, they must be able to motivate the teachers and bring out the best in them. As such, it is important for the head teachers to know their leadership and emotional intelligence behaviors to increase their leadership effectiveness. That is why this study is aimed at assessing the leadership and emotional intelligence behaviors of the head teachers. From the assessment, a proposed leadership program was formed. This serves as a tool of head teachers for their effective leadership.

\section{Framework:-}

This study was anchored on Stogdill's theory of role differentiation and group achievement and Goleman's Emotional Intelligence (EI) Theory (1999). Stogdill theory shows how the subscales are interrelated with each other. On the other hand, Goleman theorized that Emotional Intelligence has four essential dimensions that can be assessed by both the Head Teachers and Teachers objectively. Lastly, based on the results of the assessment, the researcher intended to propose a leadership capability-building program that serves as a tool of head teachers for effective leadership among their teachers.

Figure 1 illustrates the conceptual model used in the study. This study determined the leadership and emotional intelligence behaviors of the public secondary school administrators. Leadership behavior was assessed regarding the following factors: representation, demand reconciliation, tolerance of uncertainty, persuasiveness, initiation of 
structure, tolerance and freedom, role assumption, consideration, production emphasis, predictive accuracy, integration, and superior orientation. Emotional intelligence, on the other hand, was quantified using selfawareness, self-management, social awareness, and relationship management as variables. The results of the assessment were used to come up with a proposed leadership capability building program. This would be the contribution of this study to local education and leadership.

The researcher used the descriptive-correlational method of research in the entire study. According to Subong (2005), descriptive research involves collecting data to test the hypothesis or answer questions concerning the current status of the subject of the study. Descriptive data are typically collected through a questionnaire survey, an interview or observation. Moreover, correlational research attempts to determine whether, and to what degree, relationship exists between two or more quantifiable variables. The purpose of correlational study may be to establish a relationship (or lack of it) or to use relationships in making predictions.

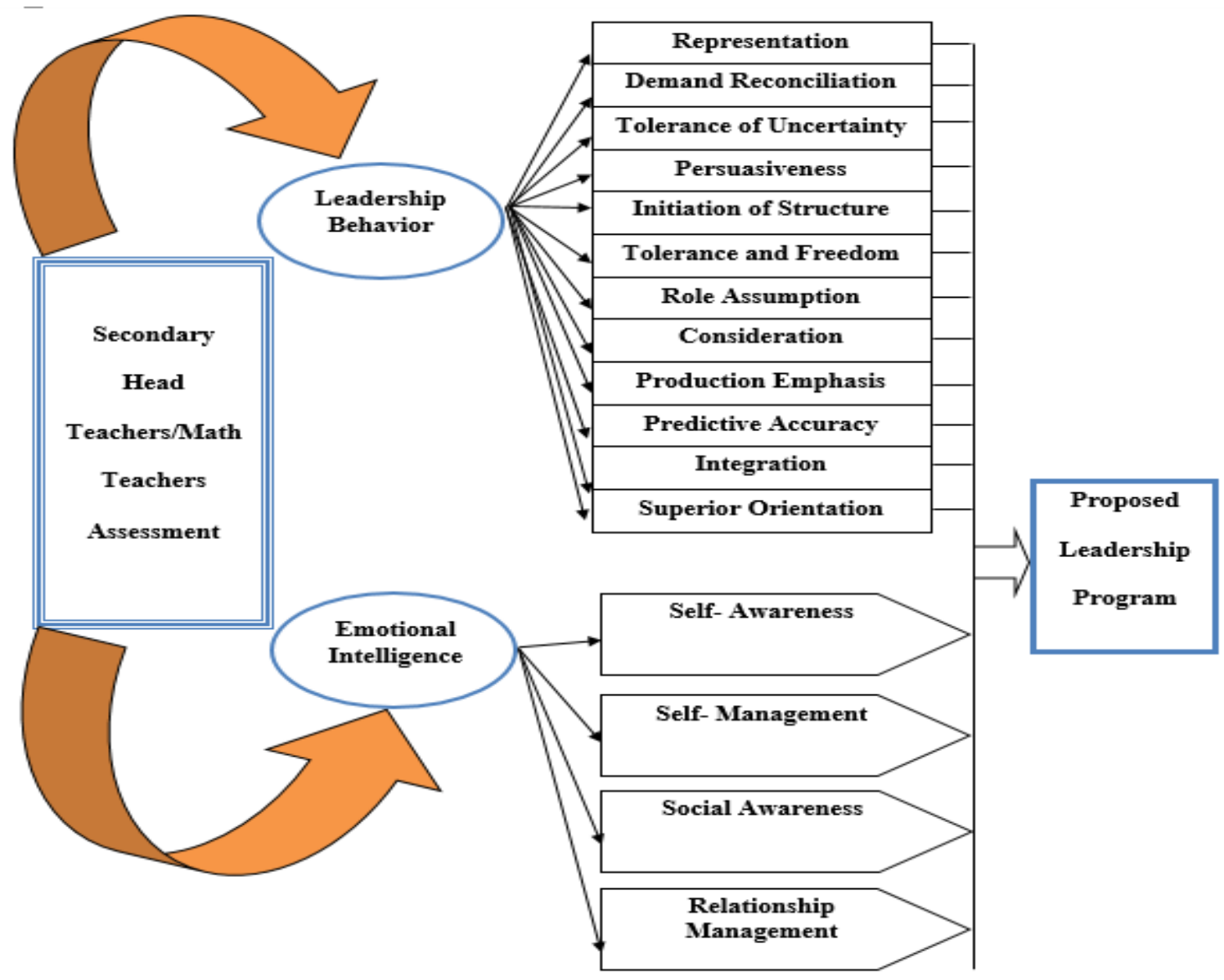

Figure 1:- Conceptual model of the study

Survey instruments that were utilized in this study were adapted from the Leadership Behavior Description Questionnaire Form XII (LBDQ - Form XII) and Emotional Intelligence Form (EI - Form) LBDQ has been utilized in different research situations including military, industrial, and educational. The EI - Form was adapted from Silver and Claret on Emotional and Leadership Development (2013).

\section{Objectives of the Study:-}

The major objective of the study was to assess the leadership behavior and emotional intelligence of Mathematics head teachers in the Division of Bulacan in aid of developing a leadership capability-building program. 
Specifically, it aimed to:

1. Assess the extent of manifestation of the leadership behavior of Mathematics Head Teachers based on self and teacher's assessment with respect to the following dimensions: representation; demand reconciliation; tolerance of uncertainty; persuasiveness; initiation of structure; tolerance and freedom; role assumption; consideration; production emphasis; predictive accuracy; integration; and. Superior orientation,

2. Determine the significance of the differences between the assessment of head teachers as to leadership behavior when grouped according to profile,

3. Assess the level of emotional intelligence of head teachers in terms of
a. self-awareness
b. self - management;
c. social awareness; and
d. relationship management,

4. Test the significance of the differences between the assessment of head teachers as to level of emotional intelligence when grouped according to profile,

5. Examine the relationship between the leadership behavior and emotional intelligence of a head teacher, and

6. Based on the findings, determine what program maybe designed and provided to develop the leadership competencies of the head teachers in school.

\section{Materials and Method:- \\ Methods and Techniques:-}

The study used the descriptive correlational method of research. According to Subong (2005), descriptive research involves collecting data to test hypotheses or answer questions concerning the current status of phenomena.

A questionnaire was used as a primary data gathering instrument in the study. The questionnaire was adapted from the Leadership Behavior Description Questionnaire Form XII (LBDQ - Form II) and Emotional Intelligence Form (EI - Form). The LBDQ has been utilized in different research situations including military, industrial, and educational. The EI - Form was adapted from Silver and Claret on Emotional and Leadership Development (2013).

\section{Interview:-}

The researcher also conducted interviews with mathematics head teachers and their teachers for the verification of their responses relative to their assessment on leadership behavior and emotional intelligence.

\section{Treatment of Data:-}

The data gathered were analyzed with the use of weighted average, t-test Pearson Product Moment Correlation and One- way Analysis of Variance.

\section{Results and Discussions:-}

Profile of the Head-Teacher Respondents:-

Profile variables include age, present position, length of service, and highest educational attainment. These variables served as baseline data for the study.

In terms of age, seven or 36.84 percent of the head teachers fell under the 48-53 age bracket. Majority of the respondents belong to the category of middle-aged professionals. Nine or 47.37 percent of the respondents had Head Teacher III as present position. Nine or 47.37 percent of the respondents had more than ten years in the present position. Majority of the head teachers had more than ten years experience in their present position. In terms of educational attainment, 11 or 57.89 percent had Bachelor's degree with MA/MS units, while eight or 42.11 percent finished a master's degree.

Leadership Behavior of Secondary Mathematics Head Teachers Based on Self and Teachers' Assessment:The Leaders Behavior Description Questionnaire, often referred to as LBDQ, was developed for use in obtaining descriptions of a supervisor by the group members whom he supervises. It can be used to describe the behavior of the leader, or leaders, in any group or organization, provided the followers have had an opportunity to observe the leader in action as a leader of their group. (Stogdill, 1963 in Richard, 2006). 
The LBDQ is composed of 100 items covering twelve dimensions: representation, demand reconciliation, tolerance of uncertainty, persuasiveness, initiation of structure, tolerance and freedom, role assumption, consideration, production emphasis, predictive accuracy, integration, and superior orientation.

\section{Representation:-}

It is the leader's ability to speak and act as the representative of the group. Table 1 shows the extent of manifestation of this leadership behavior of the head teachers.

As presented in the table, the assessment of the respondents shows that the head teachers often speak as the representative of the group with the grand weighted mean of 4.07. This shows that this leadership behavior was demonstrated all the time. The data also show the assessment of the teachers that the head teachers act as the spokesman of the group, publicize the activities of the group, speak for the group when visitors are present and represent the group at outside meetings often with grand weighted mean of 4.31 .

The overall grand weighted mean of 4.19 on the dimension of representation shows that the different leadership behaviors under these are often manifested by the teachers as assessed by both the respondents.

It can be inferred from the data that the teachers believe that their head teachers stand for them.

\section{Demand Reconciliation:-}

This dimension of leadership behaviors is defined as the leader's ability to reconcile conflicting demands are reduce disorder to system. It can be gleaned from the table that in handling complex problems efficiently, not getting swamped by details, reducing a madhouse to system and order and not getting confused when too many demands are made were often manifested often as shown by the weighted mean of 3.86. The behavior was concurred by the teachers as shown by the obtained mean value of 3.61. The overall grand weighted mean of 3.73 showed that the leadership behaviors under demand reconciliation were often manifested by the head teachers.

In an interview with some teachers in Lolomboy National High School, the teachers believe that their head teacher knows how to minimize conflicts and promote camaraderie among her teachers.

\section{Tolerance of Uncertainty:-}

Table 1 presents the extent of manifestation of leadership behavior of head teachers on the dimension tolerance of uncertainty. This dimension of leadership ability is defined as the leaders' ability to tolerate uncertainty and postponement without anxiety or upset.

The assessment shows that the head teachers often wait patiently for the results of a decision with a weighted mean of 3.49. This means that this leadership behavior was occasionally demonstrated by the head teachers. The assessment also showed that from the perspective of the teachers, the head teachers were often tolerant of uncertainty as revealed by the weighted mean of 3.61. This shows that the head teachers exhibited these leadership behaviors under tolerance of uncertainty most of the time.

In an interview, most of the respondents said that sometimes things did not go exactly as planned. They believed that this is not a sign of failure and most people who tolerate uncertainty learn that even if bad things happen, they can cope with them. The leader is the one to whom others look for assurance and clarity when threatened with uncertainty or harm (Goleman, Boyatzis, \& McKee, 2002).

\section{Persuasiveness:-}

The dimension of persuasiveness is the leader's ability to use persuasion and argument effectively and to exhibit strong convictions. The next table shows the extent of manifestation of leadership behavior of head teachers under persuasiveness.

It can be seen in the table that the respondents' assessment on leadership behavior under persuasiveness were often done like making pep talks to stimulate the group, arguments are convincing, a persuasive talker, speaking from strong inner convictions, persuading others that the ideas are to their advantage and inspiring enthusiasm for a project. It means that these leadership behaviors were demonstrated most of the time. 
The overall weighted mean of 3.82 shows that the head teachers have done or practiced the leadership behaviors under persuasiveness often. This shows that these leadership behaviors were demonstrated and applied most of the time. According to the teachers of Mariano Ponce National High School when interviewed, head teachers should persuade not manipulate. They need to use influence and persuasion, not authority. As mentioned by Kant (2012), the leader has to provide good morale and sustain the influence which involves as attempt to affect the behavior through communication. Moreover, Kondalbar (2007) stated that every group in the organization has a leader. He mentioned that a successful leader should have the ability to inspire a leader must identify each individual's capabilities, skill and inspire them.

\section{Initiation of Structure:-}

The data show the extent of manifestation of leadership behavior of head teachers under the dimension of initiation of structure. This leadership behavior deals with the leaders' ability to clearly define own role and let followers do what is expected.

As presented in the table, the head teachers often demonstrate the leadership behavior as shown by the mean value of 4.22. The findings indicate that these leadership behaviors were demonstrated and applied most of the time. The behavior under the dimension initiating structure was also assessed to have often done by the head teachers, according to the teachers. The overall grand weighted mean of 4.31 shows that the leadership behaviors under this dimension were often manifested by the head teachers based from the result of the assessment.

In the Division of Bulacan, the respondents believed that the head teachers played very active roles in directing group activities.

\section{Tolerance and Freedom:-}

Results show the extent of manifestation of leadership behavior of head teachers under the dimension of tolerance and freedom. This leadership behavior refers to the leader who allows the followers to have their scope for initiative, decision, and action.

The assessment shows that the head teachers often encourage initiative among the group members and they allow the group a high degree of initiative as shown by the grand weighted mean of 40.2. The teachers also observed the demonstration of the leadership behavior on the same scale (3.97).

The overall weighted mean of 4.02 shows that the different leadership behavior under the dimension tolerance and freedom were often manifested by the head teachers based from the assessment of both respondents. These data support Stogdill who suggested that leaders who tolerate high degrees of freedom of action tend to be described high in consideration.

\section{Role Assumptiom:-}

Presented in table 1 is the extent of manifestation of leadership behavior of head teachers under role assumption. This dimension of leadership behavior deals with the leader actively exercising the leadership role rather than surrendering leadership to others.

It can be gleaned from the table that the assessment of the respondents showed that most of the leadership behaviors under the dimension role assumption were often manifested by the head teachers. There were "I do not fail to take necessary actions', "I do not let some members take advantage of me", "I am not the leader of the group in name only", "I do not back down when I ought to stand firm", "I take full charge when emergencies arise", "I overcome attempts made to challenge my leadership", and "I am easily recognized as the leader of the group". Other leadership behaviors under this dimension were assessed as occasionally manifested.

According to head teachers, they are very much aware of their duties and responsibilities. Furthermore, they said that they exercise their role as the person in authority rather than letting any members of the group take it away from them.

As Yukl (2002), posited, "The leader defines and structures his or her role and the roles of subordinates toward the attainment of the group's formal roles." 


\section{Consideration:-}

This dimension of leadership behavior regards the comfort, well being, status, and contribution of the followers.

The table shows that the assessment of the respondents was always in "I am friendly and approachable" with a grand weighted mean of 4.21 . Other leadership behaviors in this dimension were assessed as often by the respondents.

The overall weighted mean of 4.11 shows that the head teachers have done or practiced the leadership behavior under consideration often. This means that the behaviors were demonstrated and applied most of the time.

Consideration is the extent to which leaders are concern with the well being of their followers and the extent 0 which leaders are personable and understanding. The teacher-respondents said that they want leaders who show consideration of their feelings and one who shows respect for their ideas and certain warmth among them. They want a leader who has a good rapport and practice two-way communication.

Moreover, according to the respondents, they want a leader who is friendly and approachable, treats all group members as the leaders equal, looks out for the personal welfare of group members, and makes himself/herself available to group members. This finding suggests that an effective leader should possess a strong ability to work with others and build a cohesive team. A leader must be both personable and emphatic, building camaraderie, respect, trust, and liking between leaders and followers. He should show concern for subordinates, supports them, recognizes their accomplishments and provides their welfare.

\section{Production Emphasis:-}

This dimension of leadership behavior refers to the application of pressure for productive output.

It can be gleaned from the table that the assessment of the respondents showed that the head teachers often drive hard when there is a job to be done. This leadership behavior was demonstrated and applied most of the time. Often, they encouraged overtime work, needled members for greater effort, kept the work moving at a rapid pace, pushed for increased production, asked the members to work harder, permitted the members to take it easy in their work, urged the group to beat its previous record and kept the group working up to capacity.

It can be inferred from the results that the head teachers often applied pressure for productive output. When asked about the result, the teachers said that they wanted their head teachers to be encouraging rather than putting pressure for them to work harder. Accordingly, they were driven to strive harder when they were motivated, encouraged, feel valued and cared for. When too much pressure was applied, they become unhappy and sometimes discouraged. They lacked the courage to face the challenges, but encouraging words from their head teachers helped them to take risk toward a positive change. Therefore, leadership can be very challenging but at the same time rewarding when the leader encourages and uplifts someone to a higher ground. Encouraging leaders bring out the best from their followers. They add values through believing in their potential and provide resources to help them achieve better results.

\section{Predictive Accuracy:-}

This dimension of leadership behavior exhibits foresight and ability to predict outcomes accurately.

It can be seen in the table that the respondents' assessment of the head teachers were often in making accurate decisions, being able to predict what is coming next, being accurate in predicting the trends of events and in anticipating problems and plans for them. The overall weighted mean of 3.96 shows that in exhibiting foresight and the ability to predict outcome accurately is often done. This means that the leadership behaviors under predictive accuracy were demonstrated and applied most of the time. When the head teacher-respondent of Obando School of Fisheries was asked, he replied that as a leader, he must be able to make accurate judgments. Good judgment is based on sensitivity to both the followers' performance as well as recognition of the leader's responsibility for that performance.

\section{Integration:-}

This dimension of leadership behavior deals with maintaining a closely knit organization and resolves inter-member conflicts. 
According to assessment of the respondents, the head teachers often kept the group working as a team. This means that the leadership behavior was manifested all the time. All the other leadership behaviors under the dimension of integration were assessed as often done like settling conflicts when they occurred in the group, seeing to it that the work is coordinated, helping group members settle their differences, and maintaining a closely knit group.

The overall weighted mean of the respondents' assessment showed that in resolving inter-member conflicts and maintaining closely knit organizations were done only often. This shows that the leadership behaviors under integration were demonstrated and applied most of the time.

It is a fact that conflict is everywhere. There are many situations where different people with different goals and needs have come into conflict. When the respondents were asked, they said that conflict is not too bad thing as long as it is resolved effectively. If solved, it can lead to personal and professional growth.

\section{Superior Orientation:-}

This dimension of leadership behavior deals with maintaining cordial relations with superiors, having influence with them, and in striving for higher status.

The respondents assessed that the head teachers often got along well with the people above them and kept the group in good standing with higher authority. The assessment showed that the head teachers' superiors act favorably on most of their suggestions and the head teachers enjoy the privileges of their position

Furthermore, the assessment revealed that the head teachers often worked hard for a promotion, got their superiors to act for the welfare of the group members their words carries weight to their superiors, got what they ask from their superiors, worked their way to the top, and maintained cordial relationship with supervisors. The overall weighted mean in this dimension is 3.96 which indicates that the head teachers often demonstrated the behavior; that the leadership behaviors under superior orientation were demonstrated and applied most of the time.

In an interview with the head teachers in San Miguel National High School and AFGBMTS, they said that it was important to manage relationship with the person they reported to. Building strong mutually beneficial relationships with superiors is an important key to success.

\section{Significance of Differences between the Assessment of Head Teachers and Teachers in the Leadership} behavior when Grouped According to Profile:-

The tests of significant differences conducted revealed that no significant differences exist between the assessments of the head teachers and the teachers on the twelve dimensions of leadership behavior when they are grouped according to age, present position, length of service, and educational attainment. This was shown by the obtained $\mathrm{F}$ ratios which were found lower than the critical $\mathrm{F}$ value of 3.11. The findings indicate that the null hypothesis which states that no significant differences exist in the leadership behavior of the head teachers when they are grouped according to profile has to be accepted.

Emotional Intelligence of Secondary Mathematics Head Teachers Based on Self and Teachers' Assessment:The emotional intelligence behaviors of mathematics head teachers based on self and teachers' assessment are presented per dimension of emotional intelligence such as self-awareness, self-management, social awareness, and relationship management.

\section{Self-Awareness:-}

The emotional intelligence behaviors of head teachers as regards with self-awareness were subdivided into emotional self-awareness, accurate self-assessment, and self-confidence.

One of the dimensions of self-awareness is emotional awareness. Emotional self-awareness is recognizing own emotions and the impact they have on one's life. The findings revealed that the assessment of the respondents was highest in "I can recognize my own emotions" with 4.48 weighted mean. This means that the emotional intelligence was often demonstrated often. According to the assessments of the respondents, other emotional intelligence that were demonstrated often were "I can express my own emotions," "I can describe my emotions," and "I know how my feelings impact my own performance" with weighted mean of 4.43, 4.40 and 4.30, respectively. These were 
described often demonstrated. The overall weighted mean of 4.40 shows that the emotional intelligence under the dimension emotional awareness was high.

Table 1:- Summary of Manifestation of Leadership Behavior of Head Teachers

\begin{tabular}{|c|c|c|c|c|c|c|}
\hline $\begin{array}{c}\text { Leadership } \\
\text { Behaviors }\end{array}$ & $\begin{array}{c}\text { Head } \\
\text { Teachers }\end{array}$ & DR & Teachers & DR & $\begin{array}{c}\text { Overall } \\
\text { Weighted } \\
\text { Mean }\end{array}$ & $\begin{array}{c}\text { Descriptive } \\
\text { Rating }\end{array}$ \\
\hline Representation & 4.07 & Often & 4.31 & Often & $\mathbf{4 . 1 9}$ & Often \\
\hline $\begin{array}{c}\text { Demand } \\
\text { Reconciliation }\end{array}$ & 3.86 & Often & 3.61 & Often & $\mathbf{3 . 7 3}$ & Often \\
\hline $\begin{array}{c}\text { Tolerance of } \\
\text { Uncertainty }\end{array}$ & 3.49 & Occasionally & 3.61 & Often & $\mathbf{3 . 5 5}$ & Often \\
\hline Persuasiveness & 3.62 & Often & 4.02 & Often & $\mathbf{3 . 8 2}$ & Often \\
\hline $\begin{array}{c}\text { Initiation of } \\
\text { Structure }\end{array}$ & 4.22 & Often & 4.40 & Often & $\mathbf{4 . 3 1}$ & Often \\
\hline $\begin{array}{c}\text { Tolerance and } \\
\text { Freedom }\end{array}$ & 4.02 & Often & 3.97 & Often & $\mathbf{4 . 0 0}$ & Often \\
\hline Role Assumption & 4.00 & Often & 3.78 & Often & $\mathbf{3 . 8 9}$ & Often \\
\hline $\begin{array}{c}\text { Consideration } \\
\text { Production } \\
\text { Emphasis }\end{array}$ & 4.21 & Often & 4.02 & Often & $\mathbf{4 . 1 1}$ & Often \\
\hline $\begin{array}{c}\text { Predictive } \\
\text { Accuracy }\end{array}$ & 3.93 & Often & 3.99 & Often & $\mathbf{3 . 9 6}$ & Often \\
\hline Integration & 4.44 & Often & 4.05 & Often & $\mathbf{3 . 9 6}$ & Often \\
\hline Integration & 4.44 & Often & 4.52 & Always & $\mathbf{4 . 4 8}$ & Often \\
\hline $\begin{array}{c}\text { Superior } \\
\text { Orientation }\end{array}$ & 3.89 & Often & 4.04 & Often & $\mathbf{3 . 9 6}$ & Often \\
\hline
\end{tabular}

According to Goleman, Boyatiz, and Mckee (2002), emotional self - awareness is the ability to recognize one's emotions and their effects on self and others. It is the ability to effectively read how one reacts to cues in the envirnment and be aware of how one's emotions affect performance.

On the dimension accurate self-assessment, which is identifying own strengths and limitations, the respondents' assessments were often demonstrated. The highest competency with 4.38 weighted mean was "I acknowledge my strengths and weaknesses/limitations." Accordingly, the assessment showed that the head teachers often realized the impact of his emotions on what is happening around, made career choices to leverage opportunities to learn new things or broaden one's experiences, sought out opportunities to broaden one's repertoire of capabilities, compensated his own limitations by working with others with the necessary strengths, had sense of humor about himself, and was not defensive in receiving new information or perspective about himself, and was not defensive in receiving new information or perspective about himself. The grand weighted mean of 4.19 showed that the head teachers' emotional intelligence under accurate self-assessment was high.

Burckle (2000) hypothesized that those who are rated low by others on accurate self-assessment would show less self-awareness on other competencies.

Self Confidence is "a belief in one's own capability to accomplish a task and select an effective approach to a task or problem (Goleman, 1998)." This definition includes confidence in one's ability as expressed in increasingly challenging circumstances and confidence in one's decisions or opinions.

In this dimension, which is knowing own self-work and capabilities, it can be noted that the item "I have confidence in my abilities and self-worth" obtained the highest weighted average of 4.45. This was followed by "I feel confident to work without the need for direct supervision." All items in self-confidence had a descriptive rating of often based from the result of the assessment. The overall weighted mean of 4.19 shows that the assessments of all the items were often done. This means that the assessment on the level of emotional intelligence was high. 
The overall grand weighted mean of 4.26 shows that the assessment of the respondents under self-awareness of the head teachers were often done or practiced the emotional intelligence of the head teachers as regards self-awareness was high. The head teachers believed that often they had a clear perception of their personality, including strengths and weaknesses. Being self-aware allows them to understand other people, how they perceive them, their attitude and their responses to them at the moment.

The mathematics teachers in Bulacan believe that if the leader can recognize and understand their own emotions, they have the power to control them. This kind of self-awareness makes it impossible for the emotions to rule the leader. It is said before one can make changes in himself, he has to know what there is he needs to deal with. Becoming self-aware is about the process of understanding oneself. Self-awareness can be developed. There is a need to spend some time recognizing areas one needs to improve and purposely make an effort to develop or strengthen that aspect of himself.

According to Deutschendorf (2012), leaders who are more aware can develop skills that will help them manage their own emotions, allowing them to respond more effectively to situations that come up.

Goleman (1998) argues self-awareness is critical to understanding others and exhibiting empathy. The competencies in self-awareness domain enable individuals to be cognizant of their feelings and thoughts as well as personal strengths and weaknesses. In fact, a study by Burckle and Boyatzis (1999) showed that individuals with high levels of self-management, the second domain, nearly 50 percent of the time. However, individuals with low selfawareness exhibited high levels of self-management only four percent of the time.

\section{Self-Management:-}

Self-management encompasses the emotional intelligence emotional self-control, transparency, adaptability, achievement, initiative and optimism.

\section{Emotional self-control:-}

means controlling impulsive emotions Goleman (1998) identified self-control as the ability to keep one's impulsive feelings and emotions under control and restrain negative actions when provoked, when faced with opposition or hostility from others, or when working under pressure.

It can be noted that the assessment is high in "I calm others in stressful situations," followed by "I stay composed and positive, even in trying moments." All these items were described as often done. The lowest weighted mean was obtained by the item "I resist impulse to act immediately. The grand weighted of 4.10 shows that the assessments of the respondents agreed that often, the heads could control their emotions. This means that level of emotional intelligence under this dimension was high.

\section{Transparency:-}

Also referred to as integrity, is having one's actions consistent with what one says. It includes communicating intentions, ideas, feelings openly and directly, and welcoming openness and honestly, even in difficult situations with multiple parties involved. Transparency represents congruence between what one is thinking and feeling and what one is saying and doing. People who exhibit this competency maintain integrity and take responsibility for personal performance. They act ethically and are above reproach, building trust through their reliability and authenticity. They admit their own mistakes and confront unethical actions in others. In a difficult situation, they take tough, principled stands even if they are unpopular (Goleman, 1998).

In the dimension transparency, which is also being trustworthy or being honest and taking action that is in line with values, the assessment was always in "I behave consistently with own stated values and beliefs" with weighted mean of 4.55 and "I have trustworthy in everything" with 4.53 weighted mean. The other items were given a descriptive rating of often by the respondents. The grand weighted average shows that the respondents assessed this dimension as often practiced by the head teachers. This means that the level of emotional intelligence under this dimension was high. The teachers further commented that their head teachers are trustworthy.

\section{Adaptability:-}

The ability to be flexible and to work effectively within a variety of changing situations, and with various individuals or groups was likewise assessed. Adaptability "entails understanding and appreciating different and 
opposing perspectives on an issue, adapting one's approach as the requirements of a situation change, and changing or easily accepting changes one's organization or job requirements (Goleman, 1998)."

It can be gleaned from the table that the respondents described the emotional intelligence under adaptability to have often manifested by the head teachers' level of emotional intelligence was high in adaptability. Specifically, the item which garnered the highest weighted mean of 4.41 was applying standard procedures flexibly, followed by was flexible to overcome obstacle, willingly change ideas or perceptions based on new information or contrary evidence, adapting to uncertainty and changing situations, and smoothly doing multiple demands.

The overall weighted mean of 4.21 shows that often, the head teachers are flexible. This means that the level of emotional intelligence under this dimension was high. This goes to show that the head teachers could easily adapt to new situations and could work it teachers with different culture and practices.

The dimension achievement refers to developing own performance to meet one's standards of excellence. It can be gleaned from the table that the assessment was always "I work to improve my own performance" with weighted mean of 4.56. The behavior which got the second highest weighted average of 4.38 described as often was "I make decisions, set priorities and choose goals on the basis of calculated costs and benefits." This was followed by "I set my standards and use them to judge my performance" with weighted mean of 4.32. All other behaviors under this dimension were also described as often. The overall weighted mean of 4.29 also shows that the respondents agreed in the assessment of this dimension as often, which means that the level of emotional intelligence under this dimension was high. It can be inferred that the head teachers exhibit the behavior often. They make ways to improve their performance and to improve themselves.

According to Goleman (1998), achievement is not just accomplishing things, Rather, it is accomplishing things though one's effort, against a clear, challenging standard of excellence. This competency is most effectively engaged in situations the provide immediate, concrete feedback from a credible source.

The dimension initiative means taking action when it is necessary. It can be noted that the respondents assessed that the head teachers always act in ways to do things better with weighted mean of 4.56. Moreover, the head teachers often find and act upon present opportunities, initiate action to create possibilities for the future, act rather than simply waiting to study actions of others, go beyond what is required or expected, seek information in unusual ways or from sources not typically used and cut through red tape and bends the rules when necessary to get job done. The overall weighted mean of 4.12 described as often exhibited, prove that the head teachers were able to initiate programs for the good of the department. This means that the level of emotional intelligence under this dimension was high.

Initiative is the ability to identify a problem, obstacle, or opportunity and take action in light of that address current or future problems or opportunities. Initiative should be seen in the context of proactively doing things. Those with the initiative competence act before being forced to do so by external events (Crant, 1995; Rosler, 1996).

Optimism as defined by Goleman (1998) is the persistence to pursue goals despite obstacles and setbacks. Optimism is key to achievement because it can determine one's reaction to unfavorable events or circumstances. Those with high achievement are proactive and persistent have an optimistic attitude toward setbacks, and operate from hope to success rather than fear of failure, do not often take setbacks personally, and often see obstacles as opportunity to learn and develop. The overall weighted mean of 4.35 shows that both of them agreed that optimism is manifested by the head teachers often. This means that the level of emotional intelligence under this dimension was high.

The overall grand weighted mean, which is 4.22 , of the different dimensions of self-management were described as often practiced. It can be inferred that these were practiced and exhibited by the head teachers as shown by the overall weighted mean of 4.35 shows that both of them agreed that optimism is manifested by the head teachers often. This means that the level of emotional intelligence as regards with self-management was high.

According to the head teachers, it is okay to let emotions control them, especially when it comes to positive emotions. But it is not great to be controlled by negative emotions such as anger, fear or frustrations. 
Emotional intelligence suggests that it is important for people to aware of all their emotions, and once they are aware, they can choose how they react and express their feelings. Self-management is about using self-awareness to keep negative reactions under control.

\section{Social Awareness:-}

The social awareness domain includes three competencies: empathy, organizational awareness, and following table shows the emotional intelligence behaviors of head teachers as regards with social awareness. The service orientation. Social awareness competencies determine how one handle relationships.

Empathy gives people an astute awareness of others' emotions, concerns, and needs. The empathetic individual can read emotional currents, picking up on nonverbal cues such as tone of voice or facial expression (Goleman, 1998). Empathy understands the other person's emotions, needs, and concerns.

In this dimension, it can be noted that combined assessment of the respondents show that all the items were often exhibited by the head teachers. The highest weighted mean of 4.47 was obtained by the item "I make self-available to serve and responds to the needs of their respective clients or customers. The grand weighted mean of 4.34 shows that the head teachers' empathy is often manifestedoften. This means that the level of emotional intelligence under this dimension was high.

\section{Organizational awareness:-}

Refers to one's ability to understand and learn the internal and external power relationships in an organization. Sometimes called political savvy, the organizational awareness competency includes one's ability to identify real decision makers and individuals with influence (Goleman, 1998). Organizational awareness is the ability to understand the politics within an organization and how these affect the people working in them. It can be gleaned from the table that all the items under this dimension were assessed by the respondents as often exhibited.

As assessed by the respondents, the weighted mean of 4.37 was given to the behavior "I understand the organization's values and culture' while their lowest weighted mean of 4.14 was given to "I understand the informal structures, social networks, and politics at work within the organizations.".

The grand weighted mean of 4.20 proves that the behaviors were often practiced by the head teachers. This means that the level of emotional intelligence under this dimension was high.

Service orientation is a desire to help or serve others, to meet their needs. It means focusing one's efforts on discovering and meeting the customer's or client's needs and distinguishes star sale performers from average ones (Spencer and Spencer, 1993).

Service orientation is the ability to understand and meet the needs of the clients and customers. Based from the assessment of the respondents, the head teachers often made self available to customers or clients, took personal responsibility for resolving customer of client problems non-defensively, matched customer or client needs to services or products, monitored customer or client satisfaction, maintained clear communication of mutual expectations with customers or clients, acted as a trusted advisor to a customer or client overtime, and addressed the unexpressed needs of the customer or client.

The overall weighted mean of 4.36 showed that the different items under service orientation were often manifested by the head teachers.

The overall grand weighted mean of 4.30 in the dimension social awareness was often described often as assessed by the respondents. This means that the level of emotional intelligence as regards social awareness was high.

Essentially, awareness of social situations is about carefully considering what people want and planning to communicate with them in a way that is intended to meet that need.

In the interview with the head teachers, they said that they worry that others would take advantage of them if they show too much empathy. But it was made clear to them that empathizing with someone or understanding his point of view does not mean they have to agree with his or her point of view. It is about acknowledging the emotions of 
others, being thoughtful and considerate of their feelings, and making decisions that take those feelings into consideration. It helps in building rapport with other persons.

Social awareness is not intended to be quite as calculated as manipulation. Being socially aware is a natural sense to people, taking their situations and needs into account as much as possible. As stated by Deutschendorf (2012), the more self-awareness that leaders have, the higher is their awareness of the emotions of others around them. Having an awareness of emotions, how they are created, and how they influence people to allow them to not take emotions of others, such as anger, personally. Less likely to jump to conclusions or judgment, they are more likely to get to the root of the issue and the cause of strong emotional reactions of others.

\section{Relationship Management:-}

Relationship management is the ability to inspire and influence others and sort out the conflicts that arise. It encompasses the emotional intelligence inspirational leadership, influence, developing others, changes catalyst, conflict management, building bonds, and teamwork and collaboration.

Relationship management domain contains competencies that have the most direct affect on interactions with other people. In a fundamental sense, the effectiveness of one's relationship skills hinges on one's ability to attune to or influence the emotions of another person. That ability, in turn, builds on other domain if EI, particularly SelfManagement and Social Awareness. Without the ability to control emotion al outburst or impulses and without empathy, less chance exists engage effectively in relationships (Goleman, 1998).

\section{Inspirational leadership:-}

Implies a desire to lead others. Inspirational leadership is generally, but certainly not always, shown from a position of formal authority. Those adept at inspirational leadership draw on a range of personal skills to inspire others to work together toward common goals. Inspirational leaders can articulate and arouse enthusiasm for a shared vision and mission, to step forward as needed, to guide the performance of others while holding them accountable, and to lead by example. Emotions contagious, particularly when exhibited by those at the top, and extremely successfully leaders display a high level of positive energy that spreads throughout the organization (Goleman, 2000). Leadership studies have shown the more positive the style of a leader, the more positive, helpful, and cooperative are those in the group (George \& Bettenhausen, 1990; Bachman, 1988).

The dimension inspirational leadership deals in providing a vision that motivates others. As shown in the table, the respondents assessed the head teachers to have always consistently and visibly lead by example and set a clear standard for teams and colleagues. Other items under inspirational leadership that were often assessed by the respondents were the following: "I lead by setting vision and direction rather than through formal authority or positional power," "I stimulate enthusiasm and make work exciting" and "I inspire others to action by articulating a compelling mission or vision." The grand weighted mean of 4.35 under this dimension shows that the level of emotional intelligence behaviors was high.

According to the teachers, they are motivated to do their tasks because their head teachers inspire them to do so.

Influence is the ability to persuade, convince, or impact others to get them to support a specific agenda or course of action. This emotional competence emerges over and over again as a hallmark of high performance, particularly among supervisors, managers, and executives (Spencer \& Spencer, 1993).

The findings of the study revealed that all the behaviors under this dimension were assessed by the respondents as often. Furthermore, the behavior with the highest weighted mean of 4.48 was "I express concern with own image and reputation or that one's organization," and the lowest was "I get people to "Buy-in" or take ownership of ideas or plans" with 3.62 weighted mean. With overall weighted mean of 4.08 , it can be said that the influence of the head teachers is mostly felt by the teachers. This means that the level of emotional intelligence under this dimension was high.

Developing others involves sensing people's developmental needs and building their abilities. Competence in developing others, especially among sales managers, for example, typifies those at the top of their field (Spencer \& Spencer, 1993) Although "this ability is crucial for those managing front-line work, it has also emerged as a vital skill for effective leadership at high levels " (Goleman, 2000). 
Three items under developing others that got the highest weighted averages were "I express positive expectations about others' potential," "I recognize specific strengths or development opportunities in others," and "I give timely, constructive feedback in behavioral rather than personal terms." These obtained the weighted averages of 4.45, 4.42 and 4.40 , respectively, which means often exhibited by the head teachers.

The overall weighted mean of 4.37 proves that the different items under this dimension were often practiced by the head teachers. This means that the level of emotional intelligence under this dimension was high. It can be inferred that these were practiced and exhibited by the head teachers. Recognizing the need for change and supporting the process is what change catalyst is all about. As assessed by the respondents, the highest weighted average of 4.28 was obtained by the item "I model the change expected of others", while the lowest weighted average of 4.10 was given to the item "I enlist others in pursuit of a change initiative".

The overall weighted mean of 4.37 proves that the different items under this dimension were often practiced by the head teachers. This means that the level of emotional intelligence under this dimension was high. It can be inferred that these were really practiced and exhibited by the head teachers. Being a change catalyst may take some effort, especially when change feels as if it is being forced. The effort is worth it as building strengths in this competency is key to effective change management.

Conflict management is the ability to handle difficult individuals, groups of people, or tense situations with diplomacy and tact. This competency entails finding the best solution to a given problem or disagreement. A talent of those skilled in the conflict management competence is "spotting trouble as it is brewing and taking steps to calm those involved." Here the "arts of listening and empathizing are crucial to the skills of handling difficult people and situations with diplomacy, encouraging debate and open discussion, and orchestrating win-win situations" (Goleman, 1998).

It can be gleaned from the table that the assessment of the respondents was highest in helping decrease conflicts with 4.28 weighted mean. This was followed by finding a common idea to which all parties in a conflict can endorse, communicating the positions of those involved in a conflict to all concerned, focusing disagreements on the issues or actions involved rather than on the person, and bringing disagreements and grievances into the open. All these were assessed as often manifested by the head teachers.

The overall weighted mean of 4.07 proves that the head teachers often settled disputes, differences of opinions and misunderstanding among the teachers. This shows that the level of emotional intelligence under this dimension was high.

The dimension building bonds is creating and maintaining networks. The respondents assessed that often the head teachers make and personal friendships among work associates with weighted mean of 4.49. Other criteria like "I cultivate and maintain extensive informal networks," "I seek out relationships that are mutually beneficial," and "I build rapport and keep others in the loop were also assessed by the respondents as often.

The overall weighted mean of 4.29 shows that these emotional intelligence were often manifested. This means that the level of emotional intelligence behaviors under this dimension was interpreted as high.

Teamwork and collaboration represents the ability to work cooperatively with others, to be part of a team, to work together as opposed to working separately or competitively. It means working with others toward shared goals and creating group synergy in pursuing collective goals. For this competency to be effective, the intention should be genuine. Teamwork and collaboration have taken on increased importance in the last decade with trend toward team-based work in many organizations (Goleman, 1998).

Teamwork and collaboration is about building effective teams. The Table shows that the head teachers always shared information to foster collaboration, always expressed positive expectations or respect for others at work, always identified and encouraged opportunities for collaboration across and within groups, always actively promoted a friendly climate, good morale and cooperation, always promoted group reputation with outsiders and always built team spirit creating symbols of identity and pride. However, in valuing, soliciting and using others input, the respondents assessed that this was only often manifested by the head teachers. 
The overall grand weighted mean of 4.55 shows that the head teaches always manifested these emotional intelligence. This means that their assessment on the level of their emotional intelligence under this dimension was very high.

The overall grand weighted mean of 4.27 shows that the head teachers have done or practiced the emotional intelligence as regards with relationship management was high. The relationship can be complicated, and it is difficult to predict how people respond to each other and how they work together. The different dimensions of relationship management are often associated with leadership, mostly because these are obvious areas in which leadership is associated. These dimensions under relationship management are equally important to managing personal change.

It can be deducted from Table 2 that Social Awareness garnered the highest weighted mean of 4.31, though the descriptive rating was often. It can be noted further that the assessment in all dimensions of emotional intelligence was often. This means that assessments of the respondents in the level of emotional intelligence of the head teachers were high.

It can be said that awareness of own emotions and being able to these emotions are essential abilities that support effective management of relationships. Likewise, awareness of what other groups or individuals feel, and what led to social awareness is essential as it informs the possibilities for the responses or intervention.

Summary of Emotional Intelligence Behavior of Secondary Mathematics Head Teachers Based on Self and Teachers' Assessment:-

Table 2 shows the summary of emotional intelligence behavior of secondary mathematics head teachers.

Table 2:- Summary of Emotional Intelligence Behaviors of Secondary Mathematics Teachers Based on Self and Teachers' Assessment

\begin{tabular}{|l|c|c|c|c|c|c|}
\hline \multicolumn{1}{|c|}{$\begin{array}{c}\text { Emotional } \\
\text { Intelligence }\end{array}$} & $\begin{array}{c}\text { Head } \\
\text { Teachers }\end{array}$ & DR & Teachers & DR & $\begin{array}{c}\text { Overall } \\
\text { Weighted } \\
\text { Mean }\end{array}$ & Descriptive Rating \\
\hline Self-Awareness & 4.27 & Often & 4.25 & Often & 4.26 & Often \\
\hline Self-Management & 4.21 & Often & 4.22 & Often & 4.22 & Often \\
\hline Social Awareness & 4.30 & Often & 4.33 & Often & 4.31 & Often \\
\hline $\begin{array}{c}\text { Relationship } \\
\text { Management }\end{array}$ & 4.24 & Often & 4.29 & Often & 4.27 & Often \\
\hline
\end{tabular}

Significance of Differences between the Assessment of Head Teachers and Teachers as to Level of Emotional Intelligence when Grouped According to Profile:-

Table 3 shows the significance of differences between the assessment of head teachers and their teachers as to emotional intelligence when group according to age. Results of the variance analysis revealed that no significant differences exist between the assessments of the head teachers and the teachers on the emotional intelligence of the head teachers they are grouped according to age, present position, length of service, and educational attainment. This was shown by the obtained F ratios which were found lower than the critical $\mathrm{F}$ value of 3.03.

Table 3:- Significance of Differences between the Assessment of Head Teachers and Teachers as to Level of Emotional Intelligence when Grouped According to Profile

\begin{tabular}{|c|c|c|c|c|c|c|c|c|}
\hline Leadership Behavior & $\begin{array}{c}\text { Source of } \\
\text { Variation } \\
\end{array}$ & SS & df & MS & $\mathbf{f}$ & $\begin{array}{c}\text { F } \\
\text { Crit }\end{array}$ & Int & Dec \\
\hline \multirow[t]{2}{*}{ Self Awareness } & Between Groups & 0.79 & 5 & 0.16 & \multirow[b]{2}{*}{1.89} & \multirow[b]{2}{*}{3.03} & \multirow[t]{2}{*}{ Not Sig } & \multirow{2}{*}{$\begin{array}{c}\text { Accept } \\
\text { Ho }\end{array}$} \\
\hline & Within Groups & 1.08 & 13 & 0.08 & & & & \\
\hline \multirow[t]{2}{*}{ Self Management } & Between Groups & 0.61 & 5 & 0.12 & \multirow[b]{2}{*}{4.66} & \multirow[b]{2}{*}{3.03} & \multirow[t]{2}{*}{ Not Sig } & \multirow{2}{*}{$\begin{array}{c}\text { Accept } \\
\text { Но }\end{array}$} \\
\hline & Within Groups & 0.96 & 13 & 0.07 & & & & \\
\hline \multirow[t]{2}{*}{ Social Awareness } & Between Groups & 0.66 & 5 & 0.13 & \multirow[b]{2}{*}{1.22} & \multirow[b]{2}{*}{3.03} & \multirow[t]{2}{*}{ Not Sig } & \multirow{2}{*}{$\begin{array}{c}\text { Accept } \\
\text { Ho } \\
\end{array}$} \\
\hline & Within Groups & 1.40 & 13 & 0.11 & & & & \\
\hline Relationship Management & Between Groups & 0.76 & 5 & 0.15 & 1.37 & 3.03 & Not Sig & $\begin{array}{c}\text { Accept } \\
\text { Ho }\end{array}$ \\
\hline
\end{tabular}


Except for self-management which recorded an $\mathrm{F}$ ratio of 4.66, significant at .05 alpha, the findings indicate that the null hypothesis which states that no significant differences exist in the emotional intelligence of the head teachers when they are grouped according profile has to be accepted.

\section{Significance of Relationship between the Leadership Behavior and Emotional Intelligence of Mathematics} Head Teachers:-

Table 4 presents the test of significant relationship between the leadership behavior and emotional intelligence behavior of secondary mathematics head teachers.

Table 4:- Significance of Relationship between the Leadership Behavior and Emotional Intelligence of Mathematics Head Teachers

\begin{tabular}{|c|c|c|c|c|c|c|}
\hline Variables & $\begin{array}{c}\text { Computed r- } \\
\text { value }\end{array}$ & $\begin{array}{c}\begin{array}{c}\text { Degree } \\
\text { of } \\
\text { Freedom }\end{array} \\
\end{array}$ & $\begin{array}{c}\text { Tabular } \\
\text { t- value } \\
(0.05)\end{array}$ & $\begin{array}{l}\text { Computed } \\
\text { t- value }\end{array}$ & Decision & Interpretation \\
\hline $\begin{array}{c}\text { Leadership } \\
\text { Behavior }\end{array}$ & \multirow{2}{*}{$\begin{array}{c}0.11 \\
\text { (Negligible) }\end{array}$} & \multirow[t]{2}{*}{3} & \multirow[t]{2}{*}{2.353} & \multirow[t]{2}{*}{4.24} & \multirow{2}{*}{$\begin{array}{l}\text { Reject } \\
\text { Ho }\end{array}$} & \multirow[t]{2}{*}{ Significant } \\
\hline $\begin{array}{c}\text { Emotional } \\
\text { Intelligence }\end{array}$ & & & & & & \\
\hline
\end{tabular}

The computed correlation coefficient value of 0.11 indicates a negligible relationship between the leadership behaviors and emotional intelligence behaviors of secondary mathematics head teachers, further test accepted this finding.

The test of significance shows that the computed t- value of 4.24 is greater than the tabular value of 2.353 . This led to the rejection of the null hypothesis. Therefore, at 5 percent significance level and 3 degrees of freedom, it can be claimed that there is a significant relationship between the leadership behaviors and emotional intelligence behaviors of secondary mathematics head teachers. The almost similar ratings of leadership and emotional intelligence behaviors between the two groups of respondents appear to indicate a general agreement that these behaviors were manifested by the head teachers.

As proposed by George (2000), emotional intelligence plays a particularly important role in leadership effectiveness. As reiterated by the teachers of Obando School of Fisheries, they believe that head teachers who have a good leadership skill, also possess high emotional intelligence.

Based on the results of the assessments, a proposed leadership program was conceptualized for the educational leaders to gain ideas to further enhance their leadership and emotional intelligence capabilities.

It was concluded that majority of the head teachers in the Division of Bulacan often manifest the different leadership behaviors. The head teachers have high emotional intelligence. The almost similar ratings of leadership behaviors and emotional intelligence of head teachers show a significant relationship. The teachers have high regard to their head teachers in terms of the latter's leadership and emotional intelligence behaviors. Furthermore, the leadership program may enhance further the leadership and emotional intelligence behaviors of the head teachers. 


\section{References:-}

1. Avolio \& Bass (2002), Developing Potential Across Full Range of Leadership, Mahwah NJ: Lawrence Erlbaum Associates Inc.

2. Deutschendorf, Harvey. (2012). "5 Crucial Emotional Intelligence Traits of Highly Effective Leaders". http://www.fastcompany.com/3031708/the-future-of-work/5-crucial -emotional-intelligence-traits-of-highlyeffective-leaders.

3. Emotional Intelligence Questionnaire. Adapted from Silver and Claret. www. Silverandclaret.com.

4. George, J.M. (2000). Emotions and Leadership: The role of emotional intelligence. Human relations, 53(8), 1027-1055.

5. Goleman, D. (1998). Working with emotional intelligence. New York. Bantam Books.

6. Goleman, D. (2000). Leadership that gets results. Harvard Business Review. March-April.

7. Goleman, D. (2001). Emotional Intelligence: Why It Can Matter More than IQ. London: Bloomsbury Publishing.

8. Goleman, D., Mckee, A., \& Boyatzis, R.E. (2002). Primal Leadership: Realizing the power of Emotional intelligence. Boston. Harvard Business School Press.

9. Goleman, D., Mckee, A., \& Boyatzis, R.E. (2002). Primal leadership: Realizing the Power of Emotional Intelligence. Boston. Harward Business School Press.

10. Kondalbar, V. (2007). Organizational Behaviour. New Age International (P) Limited, Publishers.99 Lenka, Samir Kumar, and Ravi Kant. "Frustration and Work Motivation of Secondary School Teachers as a Correlate of Leadership Behavior of their Heads" Vol.2, No.3, May 2012.

11. Stogdill, R. M. Handbook of Leadership: A Survey of the Literature. New York: The Free Press, 1974. In Richard, J. (2006). LEADERSHIP BEHAVIORS OF OHIO SCHOOL SUPERINTENDENTS AS PERCEIVED BY BOARD OF EDUCATION MEMBERS: A RE-EXAMINATION. https://etd.ohiolink.edu/!etd.send_file?accession=akron1161195063\&disposition=inline

12. Subong, Pablo Jr. E. (2005). Statistics for Research, Rex Book Store, Inc., Quezon City.

13. Yukl, G. (2002). Leadership in Organizations. Englewood Cliffs, NJ: Prentice Hall. 